\title{
Willingness to pay for wholesome canteen takeaway
}

Nordström, Leif Jonas

Published in:

Appetite

DOI:

10.1016/j.appet.2011.08.022

Publication date:

2012

Document version

Peer reviewed version

Citation for published version (APA):

Nordström, L. J. (2012). Willingness to pay for wholesome canteen takeaway. Appetite, 58(1), 168-179.

https://doi.org/10.1016/j.appet.2011.08.022 


\title{
Willingness to pay for wholesome canteen takeaway ${ }^{1}$
}

\author{
Jonas Nordström ${ }^{2}$
}

\begin{abstract}
The primary objective of this study was to estimate the willingness to pay (WTP) for a new intervention at the workplace: wholesome canteen takeaways (CTA), i.e. a low fat meal with a large amount of vegetables prepared at the workplace canteen that only requires re-heating. The contingent valuation method was used to elicit the WTP. Two surveys were carried out in Denmark; one large-scale Internet based survey and one survey at a workplace that introduced CTA. The results from the large-scale survey suggest that this concept attracts relevant target groups; groups of individuals with a less healthy diet, low physical activity and a high body mass index. For males and individuals with low education, who also constitute relevant target groups, the results suggest no significant difference in WTP between males and females, whereas low educated individuals have a significantly lower WTP than highly educated individuals. However, the workplace study, carried out at a hospital, found that females have a significantly higher WTP for CTA compared with males. In conclusion, the concept appears to attract relevant target groups, although for a given price a smaller fraction of low educated individuals compared to high educated individuals would be willing to buy CTA.
\end{abstract}

Key words: Workplace intervention, healthy, contingent valuation, diet, willingness to pay, fast food, takeaway meal, demand

\footnotetext{
${ }^{1}$ This is the author's Postprint version of: Nordström, L. J. (2012). Willingness to pay for wholesome canteen takeaway. Appetite, 58(1), 168-179.

${ }^{2}$ I would like to thank Lars Ovesen, the editor and two anonymous referees for helpful comments and suggestions on earlier versions of the paper, and Gitte Laub Hansen, Jørgen Dejgaard Jensen and Anne Dahl Lassen for contributing to the design of the questionnaires. The financial support from the Danish Strategic Research Council is gratefully acknowledged. E-mail: jno@life.ku.dk
} 


\section{Introduction}

Poor nutrition is an important contributor to several serious diseases, such as hypertension, dyslipidemia, type 2 diabetes, cardiovascular disease, osteoporosis, dental diseases, many common cancers and obesity (Palacios et al. 2009, WHO 2003). Although the Danes' food habits have improved during the last 15 years (Kjøller et al. 2007), the average intake of fat is still above the recommended level for all age groups, while the intake of fruit and vegetables is below the recommendation ${ }^{1}$. In general, Danish women have a more healthy diet, containing more fruit and vegetables and less fat, than men (Pedersen et al. 2010). Also, a higher intake of fruit and vegetables and a lower intake of fat have been found in groups of individuals with higher education compared to groups of individuals with a lower education (Kjøller et al. 2007).

To improve the dietary quality, it is among other things recommended to reduce the intake of fat (especially from meat and dairy products) to 30 energy percent (E\%) per day and to increase the intake of fruit and vegetables to 600 grams per day (Astrup et al. 2005). Estimates suggest that deaths from cardiovascular diseases would decrease by nine percent if the intake of fat was reduced to the recommended level (Osler et al. 2000). Besides recommendations for nutritional intake, the Danish Dietary Recommendations also state that the average Dane should increase physical activity to at least 30 minutes of moderate physical activity per day, to assist the maintenance of a healthy body weight and to prevent the development of overweight and obesity. During the last 10-20 years, there has been an increase in the prevalence of obesity in Denmark, particularly among younger age groups and groups of individuals with a short education (Kjøller et al. 2007). There is, therefore, a need for effective strategies to promote health and to reduce the prevalence of diet-related diseases.

One setting in which it is possible to implement new health promotion interventions is in the workplace. The workplace is a unique setting, since it reaches a large proportion of the adult population including those unlikely to engage in preventive health behaviour programmes (European Commission 2005, University of Crete School of Medicine 2001, Wanjek 2005, and Terborg 1986). In addition, workplace programmes are generally less expensive than those offered in the community as a whole (Hartman et al. 1995). However, a drawback of workplace interventions may be that individuals with a poor diet can feel a social pressure to change their food intake and lifestyle. 
A substantial amount of research has been undertaken at the workplace to promote weight loss (e.g. Anderson et al. 2009, Benedict and Arterburn 2008, and Morgan et al. 2011), increase physical activity (Conn et al. 2009, McEachan et al. 2011 and National Institute for Health and Clinical Excellence 2008), and improve dietary habits (e.g., Sorensen et al. 1999 and 2007, Braekman el al. 1999, De Bourdeaudhuij et al. 2007, Holdsworth et al. 2004 and Ni Mhurchu et al. 2010). Concerning intervention studies aimed at improving dietary intake, Steenhuis et al. (2004) found no significant effects on fat, fruit and vegetable intake from three types of programs: a food supply plus educational program; a labelling program; and an educational program. ${ }^{2}$ Holdsworth et al. (2004) evaluated the implementation of the Heartbeat Award (HBA) scheme, a nutrition labelling scheme used in England, and concluded that the HBA had a modest impact on dietary intake.

Sorensen et al. (1998) found a significant reduction in the intake of fat and increase in servings of fruit and vegetables as a result of an intervention consisting of, e.g. consultation with management on workplace environmental changes (including increased availability of healthy foods and reduction in the potential of exposure to occupational hazards) in combination with a health education program targeting individual behaviours. Emmons et al. (1999) found an insignificant increase in the intake of fruit and vegetables and no change in the consumption of fat as a result of an intervention consisting of both educational programs and changes to nutrition policies and practices, including both labelling and food availability.

In Denmark, education has also been used as a policy tool by Lassen et al. (2004). In this study, the authors used an eight-hour training session for all canteen staff, in five selected workplace canteens, to increase the customers' intake of fruit and vegetables at lunch. The results showed a significant increase in the total intake of fruit and vegetables for all five workplace canteens. Bandoni et al. (2011) used a similar design as Lassen et al. (2004) in combination with educating the employees, and also found a significant increase in the intake of fruit and vegetables. Although the results are mixed, Ni Mhurchu et al. (2010) generally found positive dietary outcomes for interventions based on information and education, either exclusively or in combination with environmental changes, though the size of the effect was small.

A few studies have studied the impact of price reductions and increased supply of nutritious food choices. Jeffery et al. (1994), found, e.g. that purchases of fruit and salads increased threefold as a result of an intervention which consisted of a 50 percent reduction in the price of fruit and salads in combination with an increase in fruit and salad bar choices. Findings in Wilbur et al. 
(1981) also support the hypothesis that the availability of nutritious food choices has an important impact on dietary intake. Ni Mhurchu et al. (2010) also conclude, in their review of workplace health promotion interventions, that future programs should move beyond individual education and aim to intervene at multiple levels of the workplace environment. In this study, we will therefore consider the introduction of a new concept which aims to improve the dietary habits of the employees; wholesome canteen takeaway (CTA).

This intervention implies that the employees are given the opportunity to buy a wholesome takeaway dinner, which has been prepared at the workplace canteen; a low fat meal with a large amount of vegetables that only requires re-heating. Intervening at this level of the workplace environment will not only have the potential to improve the health and well-being of the individual employee, but also the health of the employee's family, which is an additional advantage compared to interventions that just aim to improve the dietary habits of the employees, for example via interventions in the workplace canteen at lunch. The idea behind the wholesome CTA is that it should contain more vegetables and less fat than the dishes consumed by the average Dane for dinner.

A small number of companies have recently introduced canteen takeaways for their employees in Denmark. However, since the concept is new and the present market is small, it is not possible to carry out an analysis of the demand for wholesome CTA on revealed preference data. Therefore, to study the demand and willingness to pay for wholesome CTA for different types of individuals, and to evaluate the potential for this intervention, we use stated preference data from two contingent valuation surveys. The surveys include a large-scale internet survey and a survey at a firm that introduced CTA. These surveys also include information about alternative food choices and time use for potential users of wholesome canteen takeaways.

The contingent valuation method (CVM) is a survey-based economic technique for the valuation of non-market goods. In short, CVM circumvents the absence of a market for a specific good by presenting consumers with a survey market in which they have the opportunity to buy the good in question. CVM was proposed by Ciriacy-Wantrup in 1947, and the first empirical study was presented by Davis in 1963. However, the technique did not become widely used until the mid 1970s. By 1995, Carson (1997) had identified more than 2000 CVM studies. Most of the early studies had an environmental or natural resource perspective, where the aim was to value environmental goods such as recreational areas and water quality. Typically, these surveys asked how much money the respondent would be willing to pay to maintain the existence of an environmental feature, such as water quality. More recently, the method has been applied to 
value other type of goods, for example new products that have not yet entered the market. Bateman et al. (2002) outline CVM.

A shortcoming of CVM is that the respondents may find it difficult to value a new product of which they have no experience. The hypothetical payment may therefore differ from actual payments due to difficulty in correctly picturing the situation. It is, therefore, of interest to carry out a survey at a workplace that introduces CTA, to study both the WTP and demand for CTA over time, as a complement to the large-scale internet survey.

\section{Method}

The experimental plan consisted of the following steps.

The large scale survey

1. Development of a questionnaire and a contingent valuation question. Collecting information about WTP for healthy CTA, household characteristics and lifestyle factors.

2. Selection of $n=9,918$ individuals aged 18-65 years from Nielsen's web panel, stratified so that $35 \%$ are blue-collar workers. Data collection via internet-based questionnaire.

3. Analysis of the data.

The work place survey

4. Selection of a workplace where CTA was about to be introduced.

5. Collection of sales statistics for CTA (from its introduction in November 2008 until August 2010).

6. Development of a questionnaire. Collecting information about WTP for CTA and household characteristics.

7. Distribution of the questionnaire to all employees $(n=230)$ who had purchased CTA four weeks after its introduction.

8. Analysis of the data.

9. Development of a second questionnaire. Collecting information about WTP for CTA and household characteristics. 
10. Distribution of the second questionnaire to all employees who had purchased CTA at least once in the period from its introduction in November 2008 until August 2009 ( $n=$ $475)$ and $(n=254)$ randomly sampled individuals who had not purchased CTA.

11. Analysis of the data from the second survey.

12. Analysis of the sales statistics.

\section{Participants}

The large scale survey. The questionnaire was sent out to a stratified sample of Nielsen's ${ }^{3}$ web panel members aged 18 to 65 years ${ }^{4}$, stratified such that 35 percent of the respondents were bluecollar workers. ${ }^{5}$ Nielsen's panel members live in a household that owns a computer and has home internet access. In Denmark, 83 percent of the households have home internet access. The questionnaire was sent out to 9,918 respondents, of which 4,550 answered the questionnaire after two reminders, resulting in a response rate of 45.9 percent. As we are mainly interested in the demand and WTP for employees with access to a canteen, we have excluded students, pensioners, farmers and self-employed persons from the sample. The sample thus consists of persons classified as blue-collar or white-collar workers. Respondents who did not report their WTP $(n=15)$ and did not know their WTP $(n=67)$ were removed from the sample. To reduce the impact of outlying observations, 24 respondents with a body mass index (BMI) over 35 were also removed from the final sample which consisted of 2,997 respondents.

The workplace survey. Few workplaces have introduced healthy canteen takeaways as it is a relatively new concept. The main reason for choosing the workplace featured in this study was due to the fact that it is a large employer (with 4,500 employees), there is good variation in the educational level among the employees, and it introduced CTA at a relatively early stage, which allowed us to follow the process over quite a long time. The workplace, which is a hospital, is located in the Copenhagen area.

The first survey at the workplace was sent out to employees who had used the web-based ordering system to buy CTA. When CTA was introduced at the hospital, one could only buy CTA via this ordering system.

In total, 230 employees had used the web-based ordering system, of these 183 answered the questionnaire, resulting in a response rate of 79.6 percent. 20 employees stated that the price was 
of minor importance, or that they did not know their WTP for a canteen takeaway. Six employees did not give information about household characteristics. After removing these respondents, the final sample consisted of 157 individuals.

The second survey at the workplace includes employees who have used the web-based ordering system, as well as randomly selected employees. Employees who had used the web-based ordering system got the same type of web-based questionnaire as the respondents in the first survey. The randomly selected employees, who consist of randomly selected individuals at the entrance of the hospital and outside the canteen at lunch time, were given a paper version of the questionnaire. The web-based questionnaire was sent to 475 employees, of whom 233 answered, whilst 254 respondents answered the paper version.

Irrespective of the price, eight respondents stated that they were not interested in buying CTA. After removing these respondents ${ }^{6}$, and those respondents missing information about household characteristics, in addition to individuals that did not know their WTP for CTA $(n=31)$, the final sample consisted of 397 individuals.

\section{Measures}

To elicit the willingness to pay for wholesome canteen takeaways, we have used the contingent valuation method, see e.g. Bateman et al. (2002). This implies that the respondents were given information about a wholesome CTA meal and thereafter asked to state their willingness to pay for the meal.

In the large scale survey the following text was used with reference to a payment card to describe the wholesome CTA concept:

"Assume that you have a canteen at your worksite that sells 'canteen takeaway', a ready-cooked dish made in the canteen that you can bring home and warm up. How much would you maximally be willing to pay for a wholesome canteen takeaway dish, containing lean meat with sauce, 200 gram vegetables and rice (i.e., enough to satisfy one's hunger).

Lean meat can for example be ground beef ${ }^{7}$ with 5 percent fat or chicken filet. A medium sized carrot and a medium sized tomato weigh about 75 gram each." 
The respondents where then asked to mark their maximum WTP on a payment card. Table 1 shows the eight levels that the respondents could mark. In addition to these choices, they could also choose "I have no interest in buying CTA," and a "don't know" answer.

To elicit the willingness to pay for canteen takeaways at the workplace, we asked the respondents: "What is your maximum willingness to pay for a takeaway meal prepared in the canteen (given the present quality of canteen takeaway)?"

The respondents where then asked to mark their maximum WTP on the same type of payment card that we used in the large-scale web survey, with an additional choice, "The price is of minor importance." Based on the results from the first workplace survey, two additional levels of maximum WTP (DKK 40 and 50) were added to the interval DKK 35-55 in the second workplace survey, since most respondents stated a maximum WTP in this interval.

We have chosen to use the payment card as the elicitation format since it is more informative and cheaper to implement than the dichotomous choice format. These two elicitation formats are recommended by Bateman et al. (2002). The payment card is also found to be superior to the open-ended direct elicitation format since the latter, among other things, may lead to a high nonresponse rate and protest answers, Mitchell and Carson (1989) and Bateman et al. (2002).

In all surveys, the respondents were also asked questions about household characteristics, which type of food healthy canteen takeaways would replace, and what they would do with the time they would save by buying CTA instead of buying food and cooking dinner. In the large scale survey, the respondents were also asked questions about the healthiness of their diet, their level of physical activity, and their weight and height.

\section{Econometric method}

We used an ordered probability model to analyse the discrete choice WTP data from the payment cards, where the alternatives have a natural order. The advantage of applying an ordered probability model, compared to, e.g. a multinomial logit model ${ }^{8}$, is that the model account for the natural order of the alternatives in the estimation of the probabilities (see e.g. Greene 2008 or Greene and Hensher 2010). The ordered probability model is built around the latent regression: 


$$
y_{i}^{*}=\boldsymbol{\beta}^{\prime} \mathbf{x}_{i}+\varepsilon_{i}, \quad i=1, \ldots, n,
$$

where $y_{i}^{*}$ is the underlying maximum WTP for individual $i$, the vector $\mathbf{x}_{i}$ is a set of explanatory variables, $\boldsymbol{\beta}$ is a vector of parameters, and $\varepsilon_{i}$ is a residual with $E \varepsilon_{i}=0$ and $\operatorname{Var} \varepsilon_{i}=1$. From the survey, we cannot observe $y_{i}^{*}$, but we know to which of the alternatives in the payment card it belongs. For a transformation of the latent regression to the discrete choice counterpart see, e.g. Maddala (1983) or Greene and Hensher 2010. Equation (1) is also a correct model specification if there is no problem of self selection in the sample. However, for our data for which one of the choices in the payment card is, "I have no interest in CTA," there might be a selection effect, since we only observe a positive WTP for those with an interest in CTA. To account for a possible selection effect, we extend the model with a sample selection mechanism that is modelled as a univariate probit model:

$$
\begin{aligned}
d_{i}^{*} & =\boldsymbol{\alpha}^{\prime} \mathbf{z}_{i}+u_{i} \\
d_{i} & =1 \text { if } d_{i}^{*}>0 \text { and } 0 \text { otherwise, }
\end{aligned}
$$

where $\boldsymbol{\alpha}$ is a vector of parameters, $\boldsymbol{z}_{i}$ is a vector of explanatory variables for individual $i$ and $u_{i}$ is a residual. A positive WTP is observed if, and only if, $d_{i}=1$, and $\varepsilon_{i}$ and $u_{i}$ are assumed to be bivariate normally distributed, $\varepsilon_{i}, u_{i} \sim N_{2}[0,0,1,1, \rho]$, with correlation $\rho$. The selectivity aspect arises through the sampling mechanism and the correlation of the residuals. There is sample selection if $\rho$ is not equal to zero. Equation (1) can be said to be the main equation, whereas equation (2) is the selection equation.

As there is no natural mean function for the ordered probability model, the interpretation of the parameters in this model is more complicated than in an ordinary regression model, see e.g. Daykin and Moffatt (2002). The marginal effects of a change in an explanatory variable are therefore analysed via the change in the cell probabilities. The formulae used to calculate the change in cell probability for continuous and dummy variables can be found in Greene (2008, Ch22) and Greene and Hensher (2010). 
The estimations have been carried out with Limdep 9.0. For inference purposes, we use a sandwich estimator to account for heteroscedasticity.

\section{Explanatory variables}

To find out whether the healthy canteen take away concept attracts relevant target groups, for example individuals and households with a less healthy life style, we have included information about the healthiness of the diet, physical activity and the respondents' body mass index in the selection equation for the ordered probability model. The healthiness of the diet is measured by a self-reported variable, which involved the respondents being asked to state to what degree they think they have a healthy diet. The respondents could choose between four different levels of healthiness; a high degree of healthiness, some degree of healthiness, a lesser degree of healthiness, and not at all healthy. In addition, there was also a "do not know" alternative.

In the model, this information is represented by dummy variables, such that the variable "a high degree of healthiness" takes a value of 1 if the respondent had marked that choice and 0 otherwise, the variable "some degree of healthiness" takes a value of 1 if that choice was marked and 0 otherwise, etc. In the model, the reference level corresponds to the two lowest levels of healthiness, a lesser degree of healthiness and not at all healthy. Relatively few respondents $(0.93$ percent) stated that they have the lowest level of healthiness (not at all healthy).

The degree of physical exercise is also measured by a dummy variable, where the variable "more than 30 min of physical exercise per day" takes a value of 1 if the respondent has more than 30 minutes of intense physical exercise per day. Intense physical exercise can, for example, be: cycling to work or taking a walk. The BMI is calculated as the individual's weight in $\mathrm{kg}$ divided by squared lengths (in meters) of the individual. Information about the healthiness of the diet, physical activity and BMI is collected in the large-scale survey, but not in the workplace surveys.

All surveys collected information about the respondent's age, gender, labour supply (hours per week), education, and the number of adults and children in the household. In addition, the largescale survey contains information about the respondent's type of employment (blue/white-collar worker), the age of the children in the household, household income, and in which municipality the household is located. In the modelling and analysis of the data, the continuous variables were transformed to dummy variables if the econometric model supported a non-linear pattern. 
For the model based on the large-scale survey data, age and income entered as continuous variables, whereas four dummy variables were created to measure the effects of children in different age groups, 0-3 years, 4-6 years, 7-14 years and 15-18 years. The dummy variable takes a value of 1 if the household has one or more children in the age interval, and a value of 0 if the household has no children within the age interval. Labour supply (hours per week) was transformed to a dummy variable "overtime work" which takes a value of 1 if the respondent, on average, works more than 38 hours per working week, and 0 otherwise. Generally, a full-time job in Denmark corresponds to a working week of 37 hours.

Dummy variables were also created to measure the effects of gender, single adult households, education, type of employment and the household's residence. The gender variable takes a value of 1 if the respondent is a female and 0 otherwise. The variable 'single adult household' takes a value of 1 if the household consists of one adult and 0 if the household consists of two or more adults. The effects of education was measured via the dummy variable 'higher education', which takes a value of 1 if the respondent has more than 3 years of education after high school, and 0 otherwise. The respondents in the sample were either white-collar workers or blue-collar workers. The dummy variable 'white-collar worker' takes a value of 1 if the respondent is a white-collar worker and 0 otherwise. Two dummy variables were created to measure if there were any geographical differences in the WTP. One of the dummy variables takes a value of 1 if the household lives in the capital city (Copenhagen) and 0 otherwise. The second dummy variable takes a value of 1 if the household lives in Nordsjælland or surrounding municipalities ${ }^{9}$ to Copenhagen and 0 otherwise.

The explanatory variables in the work place models are the respondent's age, gender and labour supply, and the number of adults and children in the household. Gender, number of adults and number of children are represented via dummy variables in both models. The gender variable takes a value of 1 if the respondent is a female and 0 otherwise. The dummy variable 'single adult household' takes a value of 1 if the household consists of one adult and 0 if the household consists of two or more adults. Number of children is modelled via two dummy variables. One of the dummy variables takes a value of 1 if the household has one child and 0 otherwise, whereas the second dummy variable takes a value of 1 if the household has two or more children and 0 otherwise. Individuals under 17 years are classified as children.

In the model for the first workplace survey, a linear pattern was found for the continuous variables age and labour supply (measured by working hours per week). However, in the model based on the data from the second workplace study, a non-linear patter was found for these 
variables. To capture these non-linear effects, we transformed the age variable to three dummy variables representing individuals in the age intervals; 35-44 years, 45-54 years and 55 years or older. The reference individual in the model is 18-34 years old. Labour supply was divided into three categories. Part-time job (takes a value of 1 if the individual works less than 34 hours per week and 0 otherwise), full-time job (takes a value of 1 if the individual works between 34 and 38 hours per week and 0 otherwise), and overtime work (takes a value of 1 if the individual works more than 38 hours per week) and 0 otherwise. In the model, the reference individual has a part-time job.

\section{Results}

\section{The large scale survey}

Table 1 and the last column in Table 2 present summary statistics of the sample in the large-scale survey. Table 1 contains information about the respondents stated WTP for wholesome CTA, whereas the last column in Table 2 contains information about the mean values of the explanatory variables in the model.

From Table 1, we can see that 33.4 percent of the respondents stated that they have no interest in buying CTA. For those who responded with a positive WTP for CTA, 61.6 percent were willing to pay up to DKK 34 (€4.56). The results in Jensen et al. (2010) suggest that the cost for ingredients and packing amounts to approximately DKK 31 (€4.16) per serving for wholesome CTA. About 13 percent of the individuals with a positive WTP for CTA are willing to pay DKK $64(€ 8.60)$ or more.

Table 1. About here

The regression results from the sample selection equation in the ordered probability model indicate that individuals with "a lesser degree of healthiness or a not at all healthy diet" have a significantly higher probability for being interested in buying CTA compared to individuals with a diet which they described as having a "high degree of healthiness". Also groups of individuals with a diet which they described as having "some degree of healthiness" have a significantly higher probability of being interested in buying wholesome CTA compared to groups of individuals with a diet which they described as having a "high degree of healthiness"10 (Table 2). 
Individuals that engage in less than 30 minutes of physical exercise per day, also have a significantly greater interest in buying wholesome CTA compared to individuals that exercise more than 30 minutes per day. In addition, the results reveal that a higher BMI has a significantly positive effect on the probability for being interested in buying healthy CTA. The results thus suggest that the CTA concept attracts relevant target groups. In addition, the results suggest that single households have a greater interest in buying CTA compared to households with two, or more adults. On the other hand, a higher age reduces the interest in buying CTA. ${ }^{11}$

From the results for the main equation we see that the point estimate for the age variable is significantly negative (Table 2). The sign of the point estimate must, however, be interpreted with caution, since it does not tell us how all cell probabilities will be affected due to a change in the covariate. It is just for the first and last cell, that we can be sure about the sign of the change in the cell probability. The marginal effect on the cell probabilities is presented in Table 3, i.e. the change in the probability that one will choose a specific alternative (cell) in the payment card due to a change in the explanatory variable by one unit (e.g. an increase in the age by one year). The change in the probability is measured in percentage units.

The results reveal that a higher age will increase the cell probabilities for the two lowest cells, and decrease the cell probabilities for the other (higher) cells, i.e. an individual with a higher age has a greater probability of stating a maximum WTP for a healthy meal below DKK 34 (€4.56) than a younger person, and a lower probability of stating a maximum WTP above DKK 34 (Table 3). To exaggerate the marginal or partial effects from a change in age, we have presented the marginal effects for an age change of 10 years in Table $3 .{ }^{12}$ Evaluated at mean values, the table reveals that an increase in age of 10 years would increase the probability for having a maximum WTP in the lowest cell, i.e. below DKK 25 (€3.36), with 1.7 percentage points. The cell probability for the next lowest cell increases with 1.0 percentage point (Table 3 ).

Table 3 reveals that the sing change in cell probabilities will appear between cell 2 and 3 (at a price of DKK $34(€ 4.56)$ ) for all covariates in our model. Thus, a negative sign of the point estimate increases the probability for having a maximum WTP in the two lowest cells, while a positive sign decreases the probability.

Turning to the results for the other covariates in the main equation we can see that there is no significant difference in the WTP between male and females. For single adult households, the 
point estimate is significantly negative, implying that single adult households have a larger probability mass for the two lowest cell probabilities compared to households with two or more adults (Table 2). From Table 3, we see that cell probabilities for the two lowest cells (cell 0 and 1) increase with 4.5 and 2.3 percent respectively, for single adult households compared with households with two or more adults.

Although the point estimates are insignificant, the results suggest that households with children below seven years have a higher WTP for canteen takeaways than households without children in this age group (Table 2). For households with small children (0-3 years old), the marginal effects are larger than for households with children aged 4 to 6 years (Table 3). On the other hand, households with older children, aged 7 to 14 years, have a significantly lower WTP than households without children in this age group. For the two lowest cell probabilities ( 0 and 1$)$, we observe an increase in the cell probabilities of 3.4 and 1.7 percent, respectively, for households with children in the age group 7-14 years compared with households without children in this age group. The presence of children in the age group 15-18 years also lowers the WTP for canteen takeaways, this effect is however insignificant (Table 2).

Table 2. About here

In addition, the results reveal that employees who work "overtime," i.e. more than 38 hours per working week, have a significantly higher WTP for CTA than employees who work less than 38 hours per week. The results also reveal that people with a higher education (with more than 3 years of education after high school) have a significantly higher WTP than individuals with a lower education. The point estimate for white-collar worker is on the other hand strongly insignificant, which implies that there is no difference in the WTP for canteen takeaways for blue- and white-collar workers (Table 2).

Table 3. About here

Looking at regional differences, we can see that individuals living in the capital city and surrounding municipalities have a significantly higher WTP than individuals living in other areas (Table 2). The largest marginal effects on the cell probabilities are found for people living in the 
capital city, i.e. Copenhagen (Table 3). Higher income also has a significant positive effect on the WTP for wholesome canteen takeaways.

The greatest marginal effects on the WTP for wholesome CTA are found for individuals who work overtime compared with individuals who work full or part-time; for individuals who live in Copenhagen and for single adult households compared with households with two or more adults (Table 3). For individuals who work overtime, the cell probabilities for the two lowest cells (0 and 1) are 4.8 and 2.9 percent lower compared with individuals who work full or part-time. For individuals who live in Copenhagen, the corresponding cell probabilities are 7.8 and 5.8 percent lower compared with individuals who do not live in Copenhagen, Nordsjælland and the municipalities surrounding Copenhagen.

\section{Alternative food intake and time use in the large-scale survey}

The results from the large-scale survey suggest that CTA would most likely replace other types of fast food followed by pre-prepared food from supermarkets and takeaway meals from other suppliers. About $20.9 \%$ of the respondents stated that CTA would most likely replace fast food. The corresponding numbers for pre-prepared food from supermarkets and takeaway meals from other suppliers was $18.9 \%$ and $17.4 \%$, respectively. However, the difference in the percentage shares for the five first alternatives is relatively small, and it is also quite likely that CTA will replace a home-cooked dinner, or a cold dish that does not require cooking as $16.6 \%$ and $16.5 \%$ of the respondents respectively marked these alternatives. ${ }^{13}$

Considering alternative time use, the results from the large-scale survey indicate that, if the respondents bought a canteen takeaway, it is most likely that they would increase the time spent with friends and family (29.0\% stated this alternative), followed by more time spent on sparetime activities and hobbies (19.6\%). Approximately 15\% of the respondents would exercise more (the third most likely choice), while about $13 \%$ of the respondents stated that they would increase their labour supply. However, since CTA would mainly replace other types of fast or pre-prepared food, the time saved from not buying food and cooking dinner may be relatively small. 


\section{The workplace survey}

The cell frequencies for the WTP questions at workplace are presented in Table 4. The first and sixth columns describe the alternatives in the payment card for the first and second workplace survey. The other columns in the table contain information about the respondents' stated WTP for CTA from the workplace canteen, the number of individuals who marked each alternative (cell) in the payment card and their percentage share. One should note that the first survey consists of respondents that had bought CTA at a price of DKK 31 (€4.16) via the web-based ordering system. As one may expect, none of these respondents stated a WTP below DKK 25 $(€ 3.36)$. In the model for the first survey, the lowest cell (cell 0) will therefore represent the interval DKK 25-34 (€3.36-4.56).

Table 4. About here

Comparing the cell probabilities for the two surveys, we see that the WTP is higher in the first survey (Table 4). However, more than 84 percent of the employees in the second survey (that includes both users and non users) have a WTP that exceeds the price of DKK 31 (€4.16) per serving. ${ }^{14}$

The estimation results for the ordered logarithmic models are presented in Table 5. In addition, the table contains information about the mean value of the explanatory variables, see columns five and nine. From the table we see that the point estimate for females is significantly positive, at a five percent significance level, in both models. One should also note that a large fraction (more than 75 percent) of the respondents in both surveys is females. Considering labour supply, the results indicate that a larger labour supply has a significantly positive effect on the WTP for CTA. For the 2008 model, we find a significant linear effect for the continuous variable, "working hours per week", while the data in the second survey reveal a non-linear pattern. The results for the 2009 model suggest that full time working respondents and overtime working respondents have a significantly higher WTP than respondents with a part time job. In the 2008 model, the results suggest a significantly lower WTP for single adult households, while the point estimate in the 2009 model is insignificant. In none of the models are the child dummy variables significant at any common significance level (Table 5). 


\section{Table 5: About here}

In addition, the 2009 data reveal a non-linear age effect, where the results suggest that individuals with an age in the intervals 35-44 years and 45-54 years have a significantly higher WTP than individuals with an age below 35 years. The point estimate for the dummy variable representing individuals with an age of 55 years or more is, on the other hand, insignificant. The age effect has thus an inverted U-shape. We find no significant age effect for the 2008 model (Table 5). ${ }^{15}$

The marginal effects on the cell probabilities for the 2008 and 2009 ordered probability models are presented in Table 6 and 7. As can be seen from the tables, the sign change of the marginal effects takes place at a price of about DKK 35-40 (€4.70-5.37) for both models, i.e. between cell 0 and 1 for the 2008 model and between cell 2 and 3 for the 2009 model. The exception is for the dummy variable overtime work for which the sign change takes place at a price of DKK 45 (€6.04), i.e. between cell 3 and 4 . However, the marginal effect of 0.3 percentage units is not significantly different from zero.

Table 6 and 7: About here

For the statistically significant variables in the 2008 model (Table 5), we find the largest marginal effects for single adult households and for females (Table 6). For females, the results reveal that the cell probability for the lowest cell (cell 0, which represents the interval DKK 2534 (€4.16-4.56)) is 18.3 percentage units lower than it is for males. The reverse pattern is found for single adult households compared with households with two or more adults. For single adult households, we find that the cell probability for the lowest cell (cell 0) is 21.8 percentage units higher than it is for households with two or more adults. One should, however, note that the marginal effects for labour supply, working hours per week, correspond to an increase in labour supply by one hour per week. An increase of about 10 working hours per week would thus result in about the same marginal effect as that of females compared with males (Table 6).

In the 2009 model, the greatest marginal effects are found for employees who work overtime (more than 38 hours per week) compared with employees who work part-time, and for employees aged 35-44 years compared with employees aged below 35 years. Compared with 
their respective reference group, the marginal effects on the cell probabilities are about the same level for these groups of individuals. The results indicate for example that the probability of stating a max WTP for the three lowest cells (representing the intervals < DKK 25, DKK 25-34 and DKK 35-49), is about 2.5, 7 and 10 percentage units lower, respectively, for individuals who work overtime and individuals aged 35-44 years compared with their respective reference group (Table 7).

\section{Alternative food intake and time use in the workplace survey}

For the employees at the hospital, CTA would most likely replace a meal prepared at home. About 43\% (36\%) of the respondents in the 2008 (2009) survey stated that CTA would replace a warm home cooked dinner, whereas $23 \%$ in both surveys said that CTA would replace a cold dish. Compared to the respondents in the large-scale survey, a much smaller fraction (22\% in both work place surveys) would replace fast food or pre-prepared food with CTA.

Most of the employees at the hospital would increase the time they spend with friends and family (43\%, 2008 and 39\%, 2009) if they saved time by buying CTA. This is followed by increasing time spent on spare time activities and hobbies (16\%, 2008 and 22\%, 2009). These results are in line with those of the large-scale survey. For the respondents in the 2008 survey, the third most likely alternative is increased labour supply (16\%), while the third most likely alternative in the 2009 survey is increased time on spent on physical exercise $(21 \%)$. When decomposing the numbers in the 2009 survey, we find that the employees who participated in the "on site" survey would increase the time spent on physical exercise to a larger extent than the employees who used the web-based ordering system.

\section{Sales statistics at the workplace}

Figure 1 presents the number of sold portions of CTA at the hospital per month, from its introduction in November 2008 until August 2010. As can be seen from the figure, there was a relatively large demand for CTA at the beginning of the period, with the largest number of sold portions during the introductory month. During 2009, the demand stabilised at lower level. On average 830 portions per month [min 661, max 1034] in 2009 were sold. For 2010 one can observe a further decline in the demand, with an average sale of 650 portions per month. 
Figure 1. Number of CTA portions sold at the workplace since the introduction of CTA in November 2008 (month 1) until August 2010 (month 22)

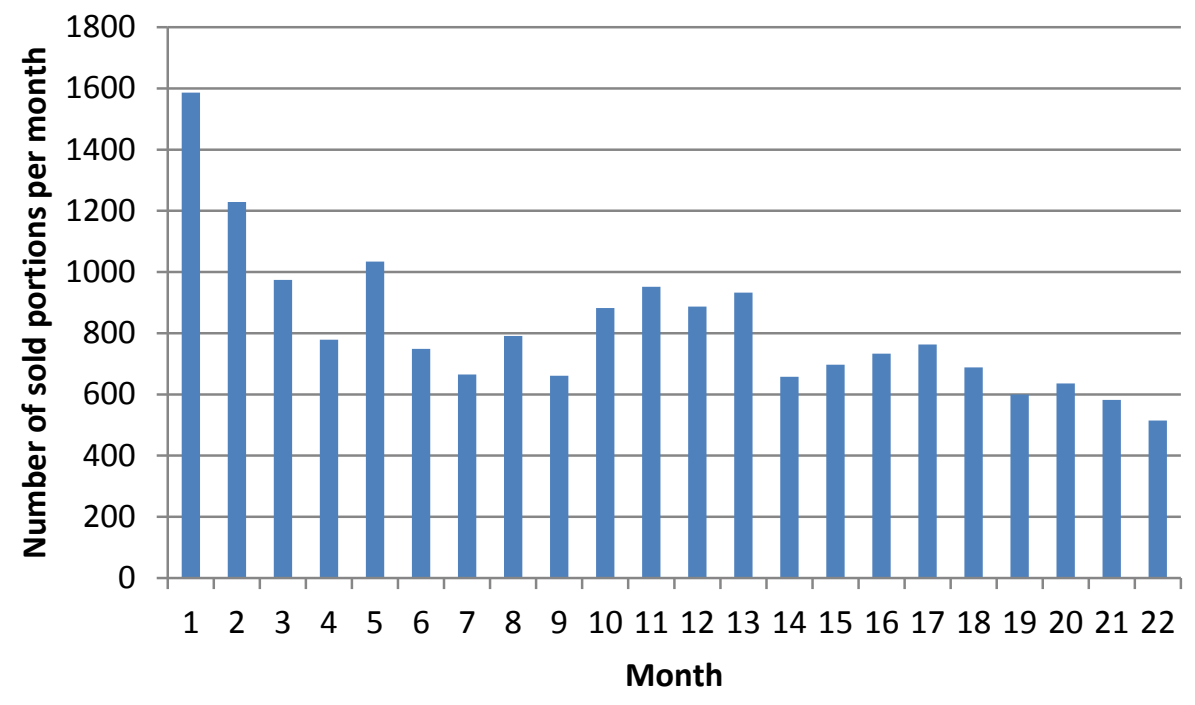

\section{Conclusions}

In this paper we have studied the willingness to pay (WTP) for wholesome canteen takeaways from workplace canteens as an intervention to improve employees' dietary habits and their worklife-balance. To elicit the WTP for wholesome canteen takeaways, we conducted two contingent valuation studies. One was a large-scale internet-based survey and the other a survey at a workplace, which had introduced canteen takeaways. In the analysis we consider the WTP for different target groups and household categories.

\section{The large-scale survey}

The results from the large-scale contingent valuation study indicate that the concept attracts relevant target groups; groups of individuals with a less healthy diet, low physical activity and high body mass index. This may indicate that CTA may be an easy way for these groups to achieve a healthier diet. Other relevant target groups in Denmark are males and individuals with low education. Generally, males have a poorer diet than females, while individuals with a low education have a poorer diet than individuals with a high education. The results reveal that there is no significant difference in the willingness to pay for wholesome canteen takeaways between 
males and females, while individuals with a low education have a significantly lower WTP for wholesome CTA compared with individuals with a high education.

In addition, the results show that younger people have both a significantly higher interest in buying wholesome canteen takeaways, and a significantly higher WTP for wholesome canteen takeaways compared to older people. This may suggest that younger people have more pressure on their time, and that CTA therefore would be a welcome addition to their routines. But it may also suggest that younger people are more interested in trying new products. Since all age groups in Denmark need to improve their diet, the results suggest that the intervention will achieve a larger health benefit for younger age groups compared to older age groups.

There is no significant difference in the WTP between households with children aged 0-6 years and households without children in this age group. However, for households with children in the age group 7-14 years, we find a significantly lower WTP for wholesome CTA compared to households without children in this age group, which may suggest that, in practice, the concept has to be adjusted to meet the needs of both households with and without children. About two thirds of the respondents say that they have an interest in buying wholesome canteen takeaways.

According to the large-scale contingent valuation survey, wholesome CTA will most likely replace other types of fast food, followed by pre-prepared food bought in supermarkets and takeaway meals from other suppliers. It is, however, also quite likely that CTA will replace a home cooked dinner, or a cold dish that does not require cooking. Considering alternative time use, it is most likely that one will increase the time with family and friends, followed by increased time on spare time activities and hobbies. However, since CTA will mainly replace other types of fast or pre-prepared food, the time saved from not buying food and cooking dinner may be relatively small.

\section{The workplace survey}

The results from the workplace, which introduced canteen takeaways, suggest that a much larger fraction of the employees had an interest in buying canteen takeaway compared to the results from the large-scale survey. This may indicate that some of the respondents in the large-scale survey may have found it difficult to imagine what a canteen takeaway would look like, and therefore stated that they had no interest in buying the product. 
However, the results from the large-scale survey and the first workplace survey suggest that the distribution of the stated WTP is quite similar for individuals with a positive WTP for canteen takeaways. ${ }^{16}$ However, the distribution of the stated WTP in the second workplace study is more compressed, with fewer respondents stating a very low or high WTP. Instead, more observations are found to be closer to the prevailing market price, which may be due to the fact that the respondents know that the product can be bought at that price. Another explanation may be that the respondents have gained additional experience of CTA and have adjusted their valuation accordingly.

In both workplace studies, females and individuals with a higher labour supply were found to have a significantly higher WTP for CTA. One explanation for the higher WTP for females may be due to the fact that they usually have greater responsibility for buying food and cooking within the household, and that CTA may make females' daily routine easier. As in the largescale survey, most respondents would increase the time spent with friends and family if they bought CTA and did not have to spend time on buying food and cooking dinner. However, contrary to the findings in the large-scale survey, most respondents in the workplace survey stated that canteen takeaways would replace a home cooked dinner, or a cold dish that does not require cooking. As this study is based on a limited number of CTA users from one workplace, it is not possible to draw any strong conclusions from this result. But it may suggest that the planning and decision process for the evening meal is fairly complex. In future research, it may therefore be a good idea to complement a hypothetical question about alternative food intake with a question about the certainty of the respondents' statement.

A shortcoming of the CVM is that it does not account for the frequency of purchase or the amount of portions that the individual aims to buy per week/month. As a complement to the CV studies at the workplace, we therefore collected sales statistics for CTA from its introduction in November 2008, until August 2010. The results show that the most portions per month were sold at the beginning of the period, and that there does not seem to be a learning, or habitual effect that generates increased demand over time. However, more observations from additional workplaces are needed to make predictions about the dynamic demand effects.

Another shortcoming of CVM is that the results may suffer from a hypothetical bias, which implies that the stated WTP may be biased upwards due to the hypothetical nature of the payment commitment. The results of the large-scale survey may also suffer from an information bias, since the respondents are forced to evaluate a new product of which they have little or no experience. The sign of the information bias is more difficult to evaluate, since it may result in 
either over-stating or under-stating the WTP. In the large-scale survey, the information bias may also have affected the number of individuals who stated that they had no interest in buying CTA.

Earlier studies that have evaluated the impact of interventions aimed at improving dietary intake at the workplace have mainly focused on the effects on the total sample and have rarely studied the impact on different household categories. An exception is Sorensen et al. (2007), who evaluated an intervention which consisted of education and information in combination with environmental changes at workplaces. The results in Sorensen et al. (2007) suggest that the intervention has a significantly greater impact on the dietary intake of females compared with males; a result that also finds support in our workplace survey, but not in the large-scale survey where no significant difference was found in the WTP between females and males.

Sorensen et al. (2007) also find a significantly positive effect on the dietary intake for single heads of households; a result that finds some support in the large-scale survey where households with one adult have a significantly higher interest in buying CTA compared with households with two or more adults. At the same time, this group of individuals has a significantly lower WTP for CTA compared with households with two or more adults. The improvement in the dietary intake for households with one adult will thus depend on the healthiness of their present diet compared with CTA and the price level of CTA. Concerning individuals with different levels of education, the results in this study are in line with the result in Sorensen et al. (2007).

The intervention in this study can also be seen as complement to the intervention in Lassen $e t$ al. (2004), who evaluate an educational program for the canteen staff (in Danish firms) aimed at increasing the customers' intake of fruit and vegetables at lunch, where CTA also has the potential to improve the dietary intake of the employee's family. 


\section{References}

Anderson, L.M., Quinn, T.A., Glanz, K., Ramirez, G., Kahwati, L.C., Johnson, D.B., Buchanan, L.R., Archer, R, Chattopadhyay, S., \& Kalra, G.P. (2009). The effectiveness of worksite nutrition and physical activity interventions for controlling employee overweight and obesity: A systematic review, American Journal of Preventive Medicine, 37(4), 340-357.

Astrup, A. Andersen, N., Stender, S., \& Trolle, E. (2005). The Danish Dietary Recommendations 2005. Ernæringsrådet and Danmarks Fødevareforskning. ISSN 0909-9859.

Bandoni, D.H., Sarno, F., \& Jaime, P.C. (2011), Impact of an intervention on the availability and consumption of fruits and vegetables in the workplace, Public Health Nutrition, 14, 975-981.

Bateman, I.J., Carson, R.T., Day, B., Hanemann, M., Hanly, N., Jones-Lee, M., Loomes, G., Mourato, S., Özdemiroglu, E., Pearce, D.W., Sugden, R., \& Swanson, J. (2002). Economic valuation with stated preference techniques: A Manual, Edward Elgar, Cheltenham, UK.

Benedict, M.A., \& Arterburn, D. (2008). Worksite-based weight loss programs: A systematic review of recent literature, American Journal of Health Promotion, 22(6), 408-416.

Braekman, L., De Bacquer, D., Maes, L., \& De Backer, G. (1999). Effects of a low-intensity worksite-based nutrition intervention, Occupational Medicine, 49(8), 549-555.

Carson, R.T. (1997). Contingent valuation and tests of scope insensitivity, in R. Kopp, W. Pommerhene, and N. Schwarts (eds.) Determining the value of non-market goods, Boston: Kluwer.

Ciriacy-Wantrup, S.V. (1947). Capital Returns from Soil Conservation Practices, Journal of Farms Economics, 29, 1180-1190.

Conn, V.S., Hafdahl, A.R., Cooper, P.S., Brown, L.M., \& Lusk, S.L. (2009). Meta-analysis of workplace physical activity interventions. American Journal of Preventive Medicine, 37(4), 330-339. 
Davis, R.K. (1963). The Value of Outdoor Recreation: An Economic Study of the Maine Woods, Ph.D. dissertation. Harvard University

Daykin, A., \& Moffatt, P. (2002). Analyzing Ordered Responses: A Review of the Ordered Probit Model, Understanding Statistics, I (3), 157-166.

De Bourdeaudhuij, I., Stevens, V., Vandelanotte, C., \& Brug, J. (2007). Evaluation of an interactive computer-tailored nutrition intervention in a real-life setting, Annals of Behavioral Medicine, 33(1), 39-48.

Emmons, K.M., Linnan, L.A., Shadel, W.G., \& Abrams, D.B. (1999). The Working Healthy Project: A Worksite Health-Promotion Trail Targeting Physical Activity, Diet, and Smoking, Journal of Occupational \& Environmental Medicine, 41, 545-555.

European Commission (2005). Green Paper - Promoting Healthy Diets and Physical Activity: A European Dimension for the Prevention of Overweight, Obesity and Chronic Diseases. COM/2005/0637. Brussels: European Commission.

Greene, W. (2008). Econometric Analysis, 6th edn. Englewood Cliffs, NJ: Prentice Hall

Greene, W., \& Hensher, D.A. (2010). Modeling Ordered Choices: A Primer, Cambridge University Press, Cambridge.

Hartman, T.J., Himes, J.H., McCarthy, P.R., \& Kushi, L.H. (1995). Effects of a low-fat, workplace intervention on blood lipids and lipoproteins, Journal of Occupational \& Environmental Medicine, 37, 690-696.

Holdsworth, M., Raymond N.T., \& Haslam, C. (2004). Does the heartbeat award scheme in England result in change in dietary behaviour in the workplace?, Health Promotion International, 19, 197-204. 
Jeffery, R.W., French, S.A., Raether, C., \& Baxter, J.E. (1994). An Environmental Intervention to Increase Fruit and Salad Purchases in a Cafeteria, Preventive Medicine, 23, 788-792.

Jensen, J., Mørkbak, M., \& Nordström, J. (2010). Economic Costs and Benefits from the Promotion of Healthy Takeaway Meals from Worksite Canteens, Mimeo University of Copenhagen.

Kjøller, M., Juel, K., \& Kamper-Jørgensen, F. (2007). Public Health Report, Denmark 2007, The National Institute for Public Health, ISBN 978-87-7899-121-8.

Lassen, A., Thorsen, A.V., Trolle, E., Elsig, M., \& Ovesen, L. (2004). Successful strategies to increase the consumption of fruits and vegetables: results from the Danish ' 6 a day' Worksite Canteen Model Study. Public Health Nutrition, 7, 263-270.

Maddala, G.S. (1983). Limited Dependent and Qualitative Variables in Econometrics, Cambridge, Cambridge University Press.

Morgan et al. (2011). Efficacy of a workplace-based weight loss program for overweight male shift workers: The Workplace POWER (Preventing Obesity Without Eating like a Rabbit) randomized controlled trail, Preventive Medicine, 52, 317-325.

McEachan et al. (2011). Testing a workplace physical activity intervention: a cluster randomized controlled trail, International Journal of Behavioral Nutrition and Physical Activity, 8:29.

Mitchell, R.C., \& Carson, R.T. (1989). Using surveys to value public goods: The contingent valuation method, Washington, DC: Resources for the Future.

National Institute for Health and Clinical Excellence (2008). Workplace health promotion: how to encourage employees to be physically active. London: National Institute for Health and Clinical Excellence. 
Ni Mhurch, C., Aston, L.M., \& Jebb, S.A., (2010). Effects of worksite health promotion interventions on employee diets: a systematic review, BMC Public Health, 10:62.

Osler, M., Godtfredsen, J., Grønbæk, M., Marckmann, P., \& Overvad, K. (2000), En kvantitativ vurdering av kostens betydning for dødeligheden af hjertesygdomme i Danmark, Ugeskrift for Lager, 37, 4921-2925.

Palacios, C., Joshipura, K.J., \& Willet, W.C. (2009). Nutrition and health: guidelines for dental practitoners, Oral Diseases, 15, 369-381.

Pedersen, A.N., Fagt, S,. Groth, M.V., Christensen, T., Biltoft-Jensen, A., Matthiessen, J., Andersen, N.L., Kørup, K., Hartkopp, H., Ygil, K-H, Hinsch, H-J., Saxholt, E., \& Trolle, E. (2010). Dietary Habits in Denmark 2003-2008. Main Results, DTU Fødevareinstitutet, ISBN 978-87-92158-67-3.

Sorensen, G., Stoddard, A., Hunt, M.K., Hebert, J.R., Ockene, J.K., Avrunin, J.S., Himmelstein, J., \& Hammond, S.K. (1998), The Effects of Health Promotion- Health Protection Intervention on Behavior Change: The WellWorks Study, American Journal of Public Health, 88(11), 1685-1690.

Sorensen, G., Stoddard, A., Peterson, K., Cohen, N., Hunt, M.K., Stein, E., Palombo, R., \& Lederman, R. (1999). Increasing fruit and vegetable consumption through worksites and families in the treatwell 5-a-day study, American Journal of Public Health, 89, 54-60.

Sorensen, G., Stoddard, A., Dubowitz, T., Barbeau, E.M. Bigby, JA., Emmons, K.M., Berkman, L.F., \& Peterson, K.E. (2007). The Influence of Social Context on Changes in Fruit and Vegetable Consumption: Results of the Healthy Directions Studies, American Journal of Public Health, 97(7), 1216-1227. 
Steenhuis, I., van Assema, P., van Breukelen, G., Glanz, K., Kok, G., \& de Vries, H. (2004). The impact of education and environmental interventions in Dutch worksite cafeterias, Health Promotion International, 19, 335-343.

Terborg, J. (1986). Health promotion at the worksite: a research challenge for personal and human resources management, Res Personal Hum Resources Manage, 4, 225-267.

Train, K. (2009). Discrete Choice Methods with Simulation, Cambridge University Press, Cambridge.

University of Crete School of Medicine (2001). EURODIET Core Report, Nutrition and diet for healthy life styles in Europe: science and policy implications, Public Health Nutrition, 4, 265-273.

Wanjek, C. (2005). Food at Work: Workplace Solutions for Malnutrition, Obesity and Chronic Diseases. Switzerland: International Labour Organisation.

WHO (2003). Diet, nutrition and the prevention of chronic diseases: report of a joint WHO/FAO expert consultation, World Health Organ Tech Rep Ser 2003;916:1-149.

Wilbur, C.S., Zifferblatt, S.M., Pinsky, J.L., \& Zifferblatt, S. (1981). Healthy Vending: A Cooperative Pilot Research Program to Stimulate Good Health in the Marketplace, Preventive Medicine, 10, 85-93. 
Tables

Table 1. Summary statistics; stated willingness to pay for canteen takeaways for respondents in the large-scale internet-based survey. The first column describes the alternatives that the respondents could mark in the payment card. The second column reports the number of individuals that marked each alternative. Columns four to seven report statistics for individuals who are interested in buying wholesome CTA; the number of individuals who marked each alternative and the percentage share, and their cumulative counterparts.

\begin{tabular}{|c|c|c|c|c|c|c|}
\hline \multirow[b]{2}{*}{ Outcome } & \multicolumn{2}{|l|}{ Frequency } & \multicolumn{2}{|l|}{ Frequency } & \multicolumn{2}{|l|}{ Cumulative } \\
\hline & Count & Percent & Count & Percent & Count & Percent \\
\hline Have no interest ${ }^{a}$ & 1000 & 33.4 & & & & \\
\hline Less than DKK 25 & 177 & & 177 & 8.9 & 1997 & 100.0 \\
\hline at most DKK 34 & 590 & & 590 & 29.5 & 1820 & 91.1 \\
\hline at most DKK 44 & 518 & & 518 & 25.9 & 1230 & 61.6 \\
\hline at most DKK 54 & 454 & & 454 & 22.7 & 712 & 35.7 \\
\hline at most DKK 64 & 155 & & 155 & 7.8 & 258 & 12.9 \\
\hline at most DKK 74 & 65 & & 65 & 3.3 & 103 & 5.2 \\
\hline at most DKK 85 & 30 & & 30 & 1.5 & 38 & 1.9 \\
\hline More than DKK 85 & 8 & & 8 & 0.4 & 8 & 0.4 \\
\hline Sum & 2997 & 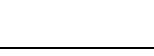 & 1997 & 100.0 & 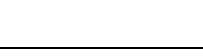 & \\
\hline
\end{tabular}


Table 2. Results from the sample selection ordered probability model* for the large-scale survey, and descriptive statistics (mean values) for the variables in the model.

\begin{tabular}{|c|c|c|c|c|}
\hline Variable & Coefficient & s.e. & $p$ & $\begin{array}{l}\text { Mean of } \\
\text { variable }\end{array}$ \\
\hline & \multicolumn{4}{|c|}{ Selection equation } \\
\hline Constant & 1.36 & 0.21 & $<0.001$ & \\
\hline \multicolumn{5}{|l|}{ A diet with a high degree of } \\
\hline healthiness, & -0.24 & 0.08 & 0.005 & 0.24 \\
\hline $\begin{array}{l}\text { A diet with some degree of } \\
\text { healthiness }\end{array}$ & -0.02 & 0.07 & 0.746 & 0.65 \\
\hline \multicolumn{5}{|l|}{ More than 30 min of physical } \\
\hline BMI & 0.02 & 0.01 & 0.018 & 25.1 \\
\hline Age $^{a}$ & -2.70 & 0.24 & $<0.001$ & 0.46 \\
\hline \multirow[t]{2}{*}{ Single } & 0.12 & 0.06 & 0.036 & 0.24 \\
\hline & \multicolumn{4}{|c|}{ Main equation } \\
\hline Constant & 0.95 & 0.14 & $<0.001$ & \\
\hline $\operatorname{Age}^{a}$ & -0.69 & 0.32 & 0.032 & 0.46 \\
\hline Gender(Female) & 0.04 & 0.05 & 0.357 & 0.52 \\
\hline Single & -0.17 & 0.06 & 0.005 & 0.24 \\
\hline \multicolumn{5}{|l|}{ Household with children } \\
\hline $0-3$ years old & 0.16 & 0.10 & 0.104 & 0.05 \\
\hline 4-6 years old & 0.05 & 0.08 & 0.534 & 0.09 \\
\hline $7-14$ years old & -0.13 & 0.05 & 0.018 & 0.24 \\
\hline $15-18$ years old & -0.03 & 0.06 & 0.609 & 0.15 \\
\hline Overtime work & 0.19 & 0.05 & $<0.001$ & 0.34 \\
\hline Higher education & 0.13 & 0.05 & 0.008 & 0.45 \\
\hline White-collar worker & 0.01 & 0.01 & 0.918 & 0.62 \\
\hline Copenhagen & 0.34 & 0.06 & 0.000 & 0.15 \\
\hline \multicolumn{5}{|l|}{ Nordsjælland \& surrounding } \\
\hline municipalities to Copenhagen & 0.12 & 0.06 & 0.047 & 0.19 \\
\hline Income $^{b}$ & 0.04 & 0.02 & 0.035 & 4.19 \\
\hline \multirow[t]{2}{*}{ Income missing } & -0.43 & 0.18 & 0.016 & 0.04 \\
\hline & \multicolumn{4}{|c|}{ Threshold parameters (main equation) } \\
\hline Threshold parameter 1 & 0.97 & 0.081 & $<0.001$ & \\
\hline Threshold parameter 2 & 1.60 & 0.114 & $<0.001$ & \\
\hline Threshold parameter 3 & 2.34 & 0.145 & $<0.001$ & \\
\hline Threshold parameter 4 & 2.82 & 0.160 & $<0.001$ & \\
\hline Threshold parameter 5 & 3.25 & 0.171 & $<0.001$ & \\
\hline \multirow[t]{2}{*}{ Threshold parameter 6} & 3.81 & 0.212 & $<0.001$ & \\
\hline & \multicolumn{4}{|c|}{ Correlation $(u, \varepsilon)$} \\
\hline $\operatorname{Rho}(u, \varepsilon)^{c}$ & 0.57 & 0.159 & 0.001 & \\
\hline Number of observations & 2997 & Chis & Iared & 6.10 \\
\hline Log likelihood function & -5066 & Degre & s of freedom & 1 \\
\hline Restricted log likelihood f. & -5069 & Prob & ChiSqd > value] & 0.014 \\
\hline \multicolumn{5}{|c|}{$\begin{array}{l}\text { Note: }{ }^{a} \text { The age variable is divided by } 100 .{ }^{b} \text { Income, is the respondents income and } \\
\text { takes a value of } 1 \text { if the income is less than DKK } 100 \text { thousand; } 2 \text { if the income is in } \\
\text { the interval DKK } 100,000-199,999 ; 3 \text { if the income is in the interval DKK 200,000- } \\
299,999 \text { and so forth up to } 9 \text { if the income is in the interval DKK } 800,000-899,999 \text {, } \\
\text { and } 10 \text { if the income is above DKK } 900 \text { thousand. }{ }^{*} \text { The model consists of two } \\
\text { equations, a selection equation modelled as a univariate probit model, and a Main }\end{array}$} \\
\hline
\end{tabular}


equation modelled as an ordered probit model. The indicator variable in the univariate probit model takes a value of 1 if the respondent is interested in buying CTA (i.e. states a positive WTP for CTA) and 0 if the respondent says that he/she is not interested in buying CTA. ${ }^{c}$ Estimated correlation between the residuals in the selection equation $(u)$ and the main equation $(e)$. There is sample selection if rho is not equal to 0 .

Table 3. Marginal effects (in percentage units) on the cell probabilities ${ }^{a}$ in the payment card for the large-scale survey. The marginal effect on the cell probabilities is the change in the probability that one will choose a specific alternative (cell) in the payment card due to a change in the explanatory variable by one unit.

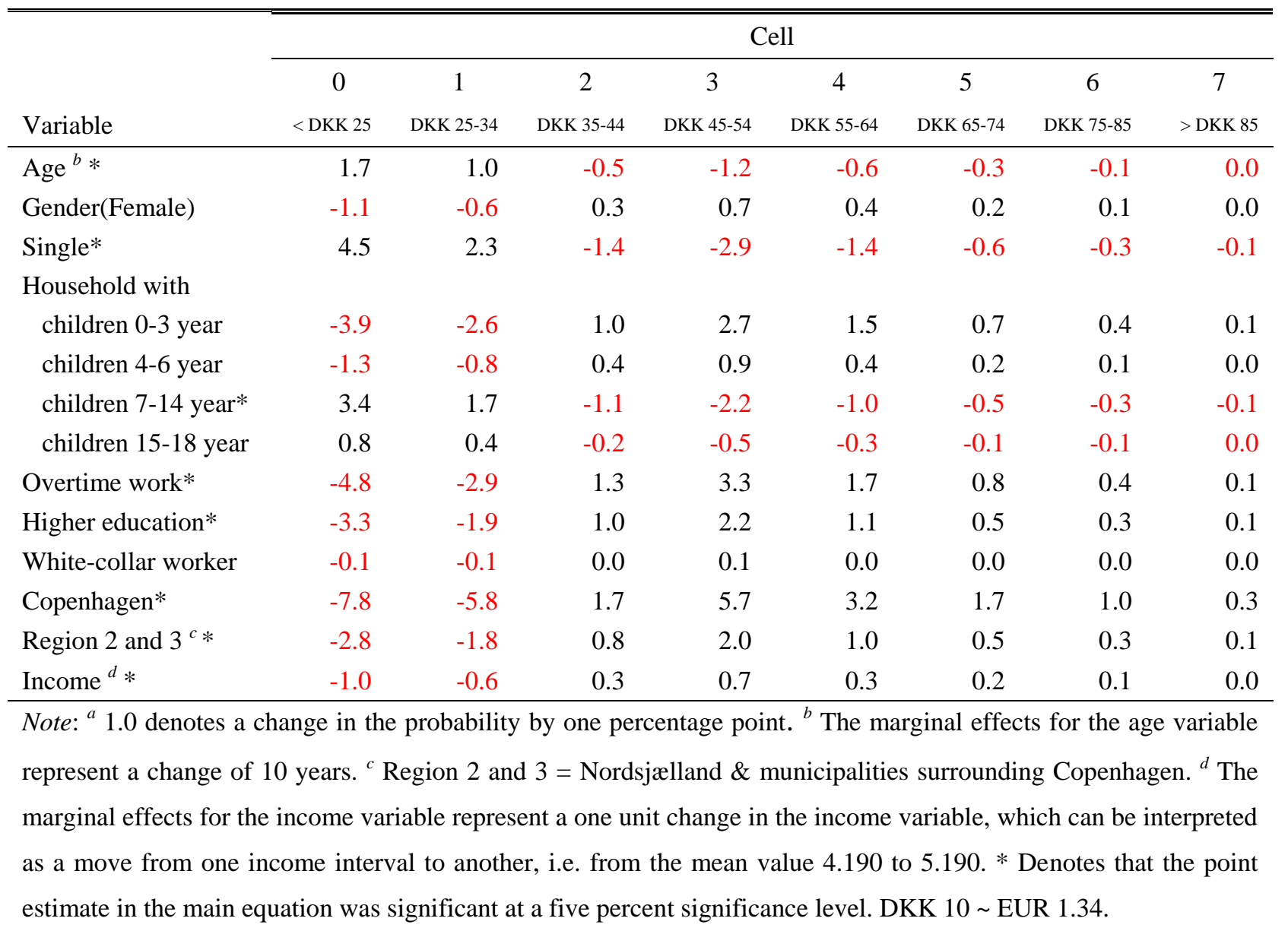


Table 4. Summary statistics, stated willingness to pay for canteen takeaways for the respondents in the workplace surveys. The first and sixth columns describe the alternatives that the respondents could mark in the payment card in the first and second workplace surveys. The second and seventh columns report the number of individuals who marked each alternative, whilst columns three and eight present the percentage share. Columns four, five, nine and ten present the cumulative counterpart.

\begin{tabular}{|c|c|c|c|c|c|c|c|c|c|}
\hline \multirow[b]{3}{*}{ Outcome } & \multicolumn{4}{|c|}{2008 years workplace survey ${ }^{a}$} & \multicolumn{5}{|c|}{2009 years workplace survey ${ }^{b}$} \\
\hline & \multicolumn{2}{|c|}{ Frequency } & \multicolumn{2}{|c|}{ Cumulative } & \multirow[b]{2}{*}{ Outcome } & \multicolumn{2}{|c|}{ Frequency } & \multicolumn{2}{|c|}{ Cumulative } \\
\hline & Count & $\%$ & Count & $\%$ & & Count & $\%$ & Count & $\%$ \\
\hline DKK 34 & 56 & 35.7 & 157 & 100.0 & $<$ DKK 25 & 15 & 3.8 & 397 & 100.0 \\
\hline DKK 44 & 63 & 40.1 & 101 & 64.3 & DKK 25 & 48 & 12.1 & 382 & 96.2 \\
\hline DKK 54 & 20 & 12.7 & 38 & 24.2 & DKK 35 & 105 & 26.4 & 334 & 84.1 \\
\hline DKK 64 & 4 & 2.5 & 18 & 11.5 & DKK 40 & 104 & 26.2 & 229 & 57.7 \\
\hline DKK 74 & 2 & 1.3 & 14 & 8.9 & DKK 45 & 35 & 8.8 & 125 & 31.5 \\
\hline DKK 84 & 10 & 6.4 & 12 & 7.6 & DKK 50 & 59 & 14.9 & 90 & 22.7 \\
\hline \multirow[t]{3}{*}{$>$ DKK 85} & 2 & 1.3 & 2 & 1.3 & DKK 55 & 16 & 4.0 & 31 & 7.8 \\
\hline & & & & & DKK 65 & 8 & 2.0 & 15 & 3.8 \\
\hline & & & & & DKK 75 & 7 & 1.8 & 7 & 1.8 \\
\hline Sum & 157 & 100.0 & & & Sum & 397 & 100.0 & & \\
\hline
\end{tabular}

Note: Outcome describes the alternatives in the payment card. In the 2008 survey, it was also possible to mark the alternative "less than DKK 25". This alternative was not marked by any respondent. ${ }^{a}$ The survey was carried out four weeks after the introduction of CTA. ${ }^{b}$ The survey was carried out nine months after the introduction of CTA. DKK $10 \sim$ EUR 1.34. 
Table 5. Results from the ordered logit models for the workplace surveys in 2008 (four weeks after the introduction of CTA) and 2009 (nine months after the introduction of CTA), and descriptive statistics (mean values) for the variables in the models.

\begin{tabular}{|c|c|c|c|c|c|c|c|c|}
\hline \multirow[b]{2}{*}{ Variable } & \multicolumn{4}{|c|}{2008} & \multicolumn{4}{|c|}{2009} \\
\hline & Coeff. & s.e. & $p$ & $\begin{array}{c}\text { Mean of } \\
\text { variable }\end{array}$ & Coeff. & s.e. & $p$ & $\begin{array}{l}\text { Mean of } \\
\text { variable }\end{array}$ \\
\hline Constant & -3.42 & 1.53 & 0.025 & & 2.15 & 0.40 & $<0.001$ & \\
\hline Gender (Female) & 0.78 & 0.33 & 0.018 & 0.76 & 0.40 & 0.20 & 0.049 & 0.79 \\
\hline Work full-time & - & - & - & & 0.51 & 0.25 & 0.043 & 0.54 \\
\hline Overtime work & - & - & - & & 0.87 & 0.29 & 0.002 & 0.19 \\
\hline Hours of work & 0.08 & 0.04 & 0.029 & 36.9 & - & - & - & \\
\hline Single & -0.91 & 0.45 & 0.043 & 0.18 & -0.23 & 0.23 & 0.307 & 0.18 \\
\hline Household with one child & -0.22 & 0.51 & 0.664 & 0.18 & 0.17 & 0.24 & 0.485 & 0.27 \\
\hline $\begin{array}{l}\text { Household with two or } \\
\text { more children }\end{array}$ & 0.39 & 0.41 & 0.340 & 0.47 & -0.23 & 0.25 & 0.355 & 0.42 \\
\hline $35-44$ years old & - & - & - & & 0.82 & 0.28 & 0.003 & 0.31 \\
\hline $45-54$ years old & - & - & - & & 0.63 & 0.26 & 0.017 & 0.28 \\
\hline 55 years or older & - & - & - & & 0.45 & 0.33 & 0.171 & 0.16 \\
\hline Age (number of years)/10 & 0.18 & 0.15 & 0.236 & 3.54 & - & - & - & - \\
\hline Threshold parameter 1 & 1.85 & 0.67 & 0.006 & & 1.59 & 0.21 & $<0.000$ & \\
\hline Threshold parameter 2 & 2.80 & 1.37 & 0.040 & & 2.99 & 0.26 & $<0.000$ & \\
\hline Threshold parameter 3 & 3.09 & 1.87 & 0.062 & & 4.12 & 0.37 & $<0.000$ & \\
\hline Threshold parameter 4 & 3.26 & 1.72 & 0.059 & & 4.59 & 0.41 & $<0.000$ & \\
\hline Threshold parameter 5 & 5.14 & 1.81 & 0.004 & & 5.87 & 0.58 & $<0.000$ & \\
\hline Threshold parameter 6 & - & - & - & & 6.64 & 0.81 & $<0.000$ & \\
\hline Threshold parameter 7 & - & - & - & & 7.43 & 0.99 & $<0.000$ & \\
\hline Number of observations & 157 & & & & 397 & & & \\
\hline Log likelihood function & -208.6 & & & & -726.4 & & & \\
\hline Restricted log likelihood f. & -216.1 & & & & -737.9 & & & \\
\hline Chi squared & 15.1 & & & & 22.9 & & & \\
\hline Degrees of freedom & 6 & & & & 9 & & & \\
\hline Prob [ChiSqd > value] & 0.019 & & & & 0.006 & & & \\
\hline
\end{tabular}

Note: The variable work full-time (takes a value of 1 if the individual works between 34 and 38 hours per week and

0 otherwise), and the variable overtime work (takes a value of 1 if the individual works more than 38 hours per week and 0 otherwise). In the model, the reference individual has a part-time job (i.e. has a labour supply below 34 hours per week). 
Table 6. Marginal effects (in percentage units) on the cell probabilities ${ }^{a}$ in the payment card for the workplace survey in 2008. The marginal effect on the cell probabilities is the change in the probability that one will choose a specific alternative (cell) in the payment card due to a change in the explanatory variable by one unit.

\begin{tabular}{|c|c|c|c|c|c|c|c|}
\hline \multirow[b]{3}{*}{ Variable } & \multicolumn{7}{|c|}{ Cell } \\
\hline & 0 & 1 & 2 & 3 & 4 & 5 & 6 \\
\hline & DKK 25-34 & DKK 35-44 & DKK 45-54 & DKK 55- 64 & DKK 65-74 & DKK 75-85 & > DKK 85 \\
\hline Gender (Female)* & -18.3 & 6.2 & 6.0 & 1.3 & 0.7 & 3.4 & 0.7 \\
\hline Hours of work* & -1.8 & 0.4 & 0.6 & 0.2 & 0.1 & 0.4 & 0.1 \\
\hline Single* & 21.8 & -8.3 & -6.8 & -1.5 & -0.7 & -3.8 & -0.8 \\
\hline Household with one child & 5.2 & -1.4 & -1.8 & -0.4 & -0.2 & -1.1 & -0.2 \\
\hline Household with two or more ch. & -8.8 & 2.0 & 3.2 & 0.8 & 0.4 & 2.0 & 0.4 \\
\hline Age (number of years) & -4.0 & 0.9 & 1.5 & 0.3 & 0.2 & 0.9 & 0.2 \\
\hline
\end{tabular}

Note: ${ }^{a} 1.0$ denotes a change in the probability by one percentage point. $*$ Denotes that the point estimate in the ordered logit model was significant at a five percent significance level. ch.= children. DKK $10 \sim$ EUR 1.34 .

Table 7. Marginal effects (in percentage units) on the cell probabilities ${ }^{a}$ in the payment card for the workplace survey in 2009. The marginal effect on the cell probabilities is the change in the probability that one will choose a specific alternative (cell) in the payment card due to a change in the explanatory variable by one unit.

\begin{tabular}{|c|c|c|c|c|c|c|c|c|c|}
\hline \multirow{4}{*}{ Variable } & \multicolumn{9}{|c|}{ Cell } \\
\hline & 0 & 1 & 2 & 3 & 4 & 5 & 6 & 7 & 8 \\
\hline & $<\mathrm{DKK}$ & DKK & DKK & DKK & DKK & DKK & DKK & DKK & $>\mathrm{DKK}$ \\
\hline & 25 & $25-34$ & $35-39$ & $40-44$ & $45-49$ & $50-54$ & $55-64$ & $65-74$ & 75 \\
\hline Gender (Female)* & -1.5 & -4.1 & -4.3 & 1.7 & 1.8 & 3.9 & 1.2 & 0.6 & 0.6 \\
\hline Work full-time* & -1.8 & -4.9 & -5.7 & 1.6 & 2.2 & 5.2 & 1.7 & 0.9 & 0.8 \\
\hline Overtime work* & -2.4 & -7.0 & -10.4 & -0.3 & 3.1 & 6.5 & 3.6 & 2.0 & 1.8 \\
\hline Single & 0.8 & 2.3 & 2.5 & -0.9 & -1.0 & -2.3 & -0.7 & -0.4 & -0.3 \\
\hline Household with one child & -0.6 & -1.6 & -2.0 & 0.4 & 0.7 & 1.8 & 0.6 & 0.3 & 0.3 \\
\hline Household with two or more ch. & 0.8 & 2.2 & 2.6 & -0.7 & -1.0 & -2.3 & -0.7 & -0.4 & -0.4 \\
\hline $35-44$ years old $*$ & -2.5 & -7.1 & -9.6 & 0.9 & 3.2 & 8.8 & 3.1 & 1.7 & 1.5 \\
\hline 45-54 years old* & -1.9 & -5.5 & -7.4 & 0.8 & 2.5 & 6.8 & 2.4 & 1.3 & 1.2 \\
\hline 55 years or older & -1.3 & -3.9 & -5.3 & 0.5 & 1.8 & 4.8 & 1.7 & 0.9 & 0.8 \\
\hline
\end{tabular}

Note: ${ }^{a} 1.0$ denotes a change in the probability by one percentage point. $*$ Denotes that the point estimate in the ordered logit model was significant at a five percent significance level. ch.= children. DKK $10 \sim$ EUR 1.34 . 


\footnotetext{
${ }^{1}$ With the exception of children between six to nine years old, who fulfil the recommendation of 400 gram of fruit and vegetables per day for children up to ten years, Kjøller et al. (2007).
}

2 The food supply program comprised an increased availability of low-fat products and vegetables in workplace cafeterias, and the educational program consisted of information about healthy nutrition through brochures, table tents, a self-help manual and posters.

${ }^{3}$ Nielsen is a market research company that was established in the United States in 1923. The company opened its first international office in the UK in 1939 and is today represented in more than 100 countries. For further information see www.nielsen.com

${ }^{4}$ Since we are interested in the workforces' willingness to pay for healthy CTA, we have restricted the age of the respondents. In Denmark, one usually retires at an age of 65 years.

${ }^{5}$ The percentage share of blue-collar workers does not reflect the actual share of blue-collar workers in Denmark, but was chosen to ensure that a sufficient part of the sample consisted of this type of employee, since they were initially considered to be an important target group.

${ }^{6}$ In the initial analysis of the data, these individuals were included in the sample, and a sample selection ordered probability model was estimated. Since the results suggested that there was no selectivity in this sample, these individuals have been removed from the final sample.

7 In Danish, 'hakkebøffer' was used to exemplify the type of meat. The ingredients for 'hakkebøffer' are lean ground beef, butter, salt and pepper.

${ }^{8}$ A drawback of the multinomial logit model is, for example, that the relative probabilities of any two outcomes are independent of probabilities of other outcomes (see e.g. Train 2009).

${ }^{9}$ Albertslund, Ballerup, Brøndby, Gentofte, Gladesaxe, Glostrup, Herlev, Hvidovre, Høje-Taastrup, Ishøj, LyngbyTaarbæk, Rødovre, Vallensbæk and municipalities in Nordsjælland. Additional dummy variables were created for other regions, but turned out to have an insignificant effect in the statistical analysis. To obtain a parsimonious parameter specification, these variables where not included in the final model specification.

${ }^{10}$ The regression results from a probit model with the dummy variable high degree of healthiness as dependent variable and a constant, female, higher education, age, white-collar worker, single and income as explanatory 
variables reveal that the variables female, higher education, age, and white-collar worker are significantly positive, whereas the point estimate for single is significantly negative.

11 In the initial specification of the selection equation, we also included the variables that represent household/individual characteristics in the main equation, see Table 2. However, in the final specification, we removed the insignificant variables to avoid an over-parameterized model.

${ }^{12}$ Note that this just implies that the effects in Table 3 are 10 times larger than the effect of change of one year.

${ }^{13}$ The respondent was allowed to mark two alternatives. The figures represent the real percent, i.e. the percentage shares have been normalised such that they sum to 100 percent.

${ }^{14}$ For the respondents that answered the "on site" questionnaire at the workplace in 2009, 175 out of 252 had not used CTA. The main reason for not buying CTA was that they prefer home cooked food (59 respondents) and that they were unaware of the possibility to buy CTA. Twenty four respondents found it difficult to transport the food to their home and keep the food cool. More than one reason could be reported.

${ }^{15}$ Contrary to the result from the large-scale survey, we find no support for a significant difference in the WTP for CTA between individuals with different educational levels in the workplace surveys. To obtain a parsimonious parameterisation, the respondents' educational level was not included as an explanatory variable in the final specifications of the econometric models for the workplace surveys.

${ }^{16}$ For example, stated that they have a WTP above DKK 44 (€5.91) while about 12 percent stated that they have a WTP above DKK 64 (€8.60) in both surveys. 